\title{
Intraoperative cell salvage in South Africa: Feasible, beneficial and economical
}

L Solomon, ${ }^{1,2} \mathrm{MB}$ ChB, DA (SA); R P von Rahden, ${ }^{1,2} \mathrm{BSc}, \mathrm{MB}$ BCh, Adv Dipl Appl Physiol, DA (SA), FCA (SA), Cert Critical Care (Anaes) (SA); N L Allorto, ${ }^{1,3}$ MB ChB, FCS (SA), MMed (Surgery)

${ }^{1}$ Nelson R Mandela School of Medicine, University of KwaZulu-Natal, Durban, South Africa

${ }^{2}$ Pietermaritzburg Department of Anaesthesia, Critical Care and Pain Management, Grey's Hospital, South Africa

${ }^{3}$ Department of Surgery, Pietermaritzburg Metropolitan Complex, South Africa

Corresponding author: L Solomon (lukeandleigh@gmail.com)

\begin{abstract}
Background. Healthcare services in KwaZulu-Natal (KZN) frequently experience shortages of blood products. Alternatives to traditional blood sources are needed. One possibility is cell salvage and autologous blood transfusion. Few data exist relating to their use in the South African context.

Objectives. To ascertain whether cell salvage (CS) is beneficial, feasible and economical in our setting, with the anticipation that results would excite further studies and potentially change current practice and improve existing protocols.

Methods. This study reviewed current intraoperative Cell Saver use at Grey's and Edendale hospitals in Pietermaritzburg, KZN. Current practices were observed and compared with the costs of the equivalent amount of red cell concentrate (RCC) purchased from the South African National Blood Service (SANBS). All cases of Cell Saver usage over a 1-year period from July 2012 to June 2013 were analysed.

Results. The total volume of blood transfused from CS was $55735 \mathrm{ml}$, approximately equivalent to $186 \mathrm{RCC}$ units. The comparative cost of equivalent units of RCC from SANBS was R258 445. The total cost of Cell Saver disposables during the study period was R206 047, or R263 478 when Cell Saver machine depreciation costs were included. More than one CS blood unit was available for transfusion in $66 \%$ of cases. No additional staff were required to operate the Cell Saver, which was successfully used by medical officers.

Conclusions. This study showed that intraoperative CS use is feasible, has potential patient benefit by reducing blood bank blood transfusion, and is financially comparable to purchasing the equivalent number of SANBS RCC.
\end{abstract}

S Afr Med J 2013;103(10):754-757. DOI:10.7196/SAMJ.7355

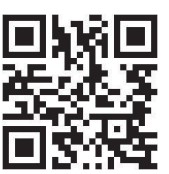

Healthcare services in KwaZulu-Natal (KZN), South Africa (SA) frequently experience shortages of blood products. This problem is common worldwide, but is particularly prevalent in Africa. ${ }^{[1]}$ Blood shortages and the associated delays in supplying appropriate blood products impact negatively on patient care. Many emergency surgical interventions involve trauma and require blood immediately without the benefit of advance warning. ${ }^{[2]} \mathrm{HIV}$ prevalence has placed an additional burden on blood supplies by limiting the number of potential donors. Alternatives to traditional blood sources need to be found. ${ }^{[3]}$

One option is cell salvage (CS) and reinfusion of autologous blood. Misconceptions regarding the use of this system are common, ${ }^{[4]}$ and few data exist relating to its use in the SA context. The benefit, feasibility and cost-effectiveness of intraoperative CS use has been questioned, ${ }^{[5]}$ but extrapolation to the SA context is difficult, particularly as the sole published trial of $\mathrm{CS}$ in $\mathrm{SA}^{[2]}$ included only patients with penetrating abdominal trauma.

There are three main steps during intraoperative CS. Blood is suctioned from the surgical field using a double-lumen suction device, which adds heparinised saline to salvaged blood. The resulting mixture goes through a filter to a collection reservoir and then enters a spinning bowl where separation of red blood cells (RBCs) occurs through centrifugation. The RBC component is kept in the bowl while the lighter components move into the waste bag. Optical sensors detect a precise haematocrit (HCT). When the correct HCT is obtained, the machine begins to wash the salvaged blood. Normal saline is pumped into the spinning centrifuge system, passing through the heavier RBC component and out into the waste line displacing the residual waste products (anticoagulant, cell debris, free haemoglobin, plasma). The RBCs are added to normal saline to obtain an HCT between $50 \%$ and $60 \%$ and are then pumped into a bag ready for transfusion. ${ }^{[6,7]}$ The disposable components for suctioning and collection of blood are supplied separately from the components that perform further processing into washed packed cells (Fig. 1). It is common practice to initially set up only the suctioning component (reservoir, suction line and anticoagulant) for blood collection and only set up the components for cell processing when enough blood has been collected to achieve a useful yield of processed cells. This

\begin{tabular}{l|l|}
\hline \multicolumn{1}{|c|}{ Collection } & Separation \\
& \\
&
\end{tabular}

Fig. 1. Stages of cell salvage and the relevant setup required. 
strategy keeps costs down in the event of a less-than-expected yield of salvaged blood, while still allowing for easy availability of the Cell Saver during emergency procedures. The decision to use CS depends on the team managing the patient intraoperatively and is typically determined by the clinical situation. ${ }^{[8]}$

Many different cases may be appropriate for CS. Indications for use should be individualised within the setting in which they are performed. Patient-specific factors as well as the local context, including financial and blood bank availability, influence the decision of when to use CS. International guidelines suggest that procedures in which CS can be useful include cardiac valve replacement, bypass grafting, major spinal surgery, thoracoabdominal aortic aneurysm repair and transplant surgery. ${ }^{[8]}$ These types of procedures are rarely/never performed at the hospitals on which this study is based. However, both hospitals have a high burden of trauma, and obstetrics and gynaecology $(\mathrm{O} \& \mathrm{G})$. These two disciplines have not traditionally been considered for CS owing to a perceived potential for complications. ${ }^{[4]}$

The Association of Anaesthetists of Great Britain and Ireland issued guidelines in 2009 that provide indications for intraoperative CS. ${ }^{[9]}$ These include: the estimated loss of blood of $>1000 \mathrm{ml}$ or $>20 \%$ of the patient's blood volume; low initial haemoglobin or patients that are at risk for bleeding; patients with unusual antibodies and blood types; and patients who decline transfusion of allogeneic blood.

\section{Objective}

To ascertain whether CS is beneficial, feasible and economical in our setting, with the anticipation that results would excite further studies and potentially change current practice and improve existing protocols.

\section{Methods}

The study was conducted at Grey's and Edendale hospitals (in the Pietermaritzburg area of KZN). Grey's Hospital is a referral hospital with 420 active beds, providing 20\% regional and $80 \%$ tertiary services. Edendale is a regional and district level hospital with 900 beds ( 480 regional and 420 district). Both hospitals cater to the needs of similar patient profiles with many trauma and obstetric cases. Moreover, patients are frequently transferred between these two hospitals, according to bed and resource availability. The doctors of the Pietermaritzburg Department of Anaesthesia, Critical Care and Pain Management (PDACCPM), who are responsible for the use of Cell Saver devices, represent a single staff pool who serve both hospitals.

Each hospital had a Cell Saver 5+ autologous blood recovery system (Haemonetics, USA) at the start of the study, and in May 2013 Edendale acquired an additional Cell Saver Elite machine (Haemonetics, USA). The machines were purchased prior to or separate from the study.

A database was created to collate the cases where the Cell Saver was set up in the theatres and intensive care units over a 1-year period from July 2012 to June 2013. Data were collected by doctors in the PDACCPM using a simple questionnaire. Anaesthetists are responsible for the setup and operation of the Cell Saver device for all cases in these hospitals. Completing the questionnaire was voluntary and no patient details were recorded to retain patient confidentiality. The questionnaire was to be filled in whenever initial setup of the CS was performed irrespective of whether or not blood was processed or transfused. All patients in whom CS was considered were eligible for inclusion in the database, with no qualifying criteria.

Data collection was via collection forms attached to each of the Cell Saver machines for easy access. Information collected included: date and time of the procedure, urgency of the case, type of procedure, discipline responsible for the patient, reasons for considering the case appropriate for Cell Saver use, reasons for not continuing to processing or transfusion (where applicable), and the amounts collected, processed and transfused.

Cost analyses were performed based on $2012 / 13$ prices. ${ }^{[10,1]}$ The cost of red cell concentrate (RCC) transfusions from the local SA National Blood Service (SANBS) blood bank increased in April 2013 and cases from April to June 2013 were costed at the new price. Consumables that were actually used were costed at the relevant prices (Fig. 1). The CS costs were compared with the cost of the equivalent volume of RCC from the blood bank, excluding crossmatch. CS blood having an HCT of $50-60 \%$ and no platelets or clotting factors is similar to RCC. The CS blood was rounded to the nearest $300 \mathrm{ml}$ to allow for comparison with the number of equivalent units that would otherwise have been ordered from SANBS.

The purchase cost of the machine and its maintenance were considered. The 2013 purchase price for the Haemonetics Cell Saver 5+ is R200 000 with costs of R1 500 per annum to service (A Rex, Product Manager, Belmont \& Haemonetics Cell Saver, SA - personal communication). Allowing for depreciation over 5 years, ${ }^{[12]}$ this equates to approximately R41 500 per year. The Haemonetics Cell Saver Elite costs R61 500 per year (A Rex, Product Manager, Belmont \& Haemonetics Cell Saver, SA - personal communication). As the Haemonetics Cell Saver 5+ was used in all the cases, except two, this machine was used for cost analysis. These costs were added to the consumable costs.

The decision to set up the disposables and to continue to CS processing was made by anaesthetists based on clinical judgement and available protocols. The current PDACCPM guideline suggests a threshold of $800 \mathrm{ml}$ of salvaged blood as being likely to produce a final yield of 1 unit $(300 \mathrm{ml})$ of Cell Saver blood. Partial and full setup was recorded and used to accurately calculate the cost of the overall Cell Saver consumables for the study period.

\section{Results}

A total of 144 forms were completed. In $80 / 144$ cases blood was generated from processing, equating to a total of $55735 \mathrm{ml}$, which is the equivalent of 186 units of RCC from the SANBS.

The number of units available after processing on a case-to-case basis is shown in Fig. 2. Approximately one-third of cases (32.5\%) resulted in a single unit available for transfusion, with the remaining cases $(67.5 \%)$ resulting in $>1$ unit available after processing.

In 22 cases the Cell Saver was set up because there was no RCC available for the patient at the blood bank. Fifteen of these cases resulted in the patient receiving blood from CS with a total of $8143 \mathrm{ml}$ being transfused. Of these patients, 10 received $>1$ unit from the CS when no other blood was available.

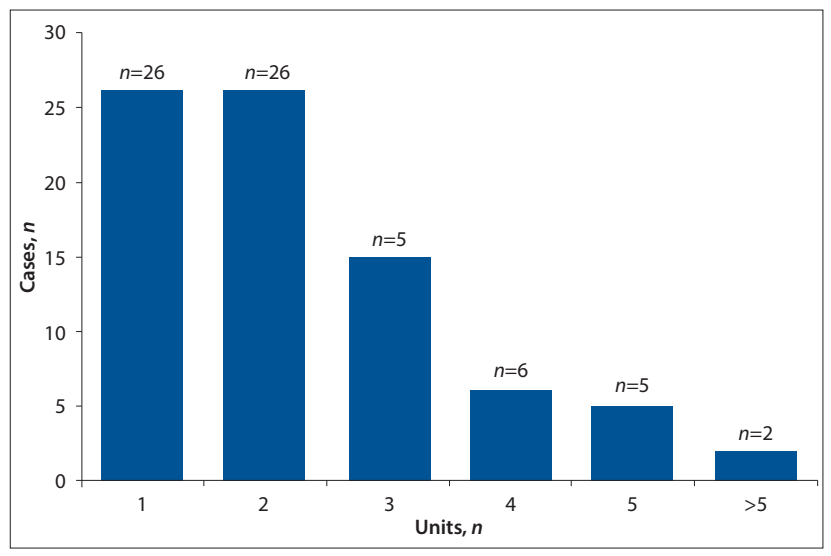

Fig. 2. Blood units available after processing - per case. 
The majority of cases in the study were emergency cases (92\%). Of these, 80 led to reinfusion of CS blood and 64 did not. There were 12 elective cases, five of which resulted in transfusion.

Fig. 3 shows the use of CS by discipline and summarises CS use and whether there was blood available for transfusion. Trauma and O\&G accounted for the majority of the cases (88\%). In $58 \%$ of trauma and $59 \%$ of O\&G cases there was ultimately Cell Saver-generated blood available for transfusion. There were insufficient cases from the other surgical disciplines for inclusion. Of the trauma cases, the instances of precordial stab wounds were more likely to continue onto processing $(n=14 / 21)$ and the data suggest vascular trauma to be a potential area where CS may show particular benefit (6/7 cases of vascular trauma received blood from CS). Ruptured ectopic pregnancies most commonly went onto CS and transfusion (amounting to 32/42 in the obstetrics group). The other disciplines had too few cases to allow for comment although it was noted that all four total hip replacements ultimately received CS transfusions.

Regarding cases where only partial setup of the Cell Saver was completed, reasons for failure to proceed to CS transfusion are summarised in Fig. 4. Where an inadequate amount of blood was collected to warrant processing, there was an average of $473 \mathrm{ml}$ collected, which is below the recommended minimum volume

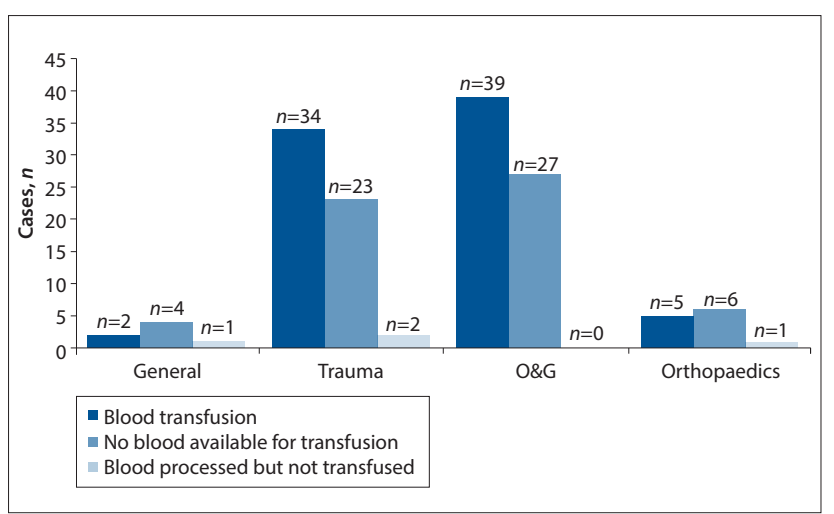

Fig. 3. Cases resulting in transfusion - by discipline $(O \hookleftarrow G=$ obstetrics and gynaecology).

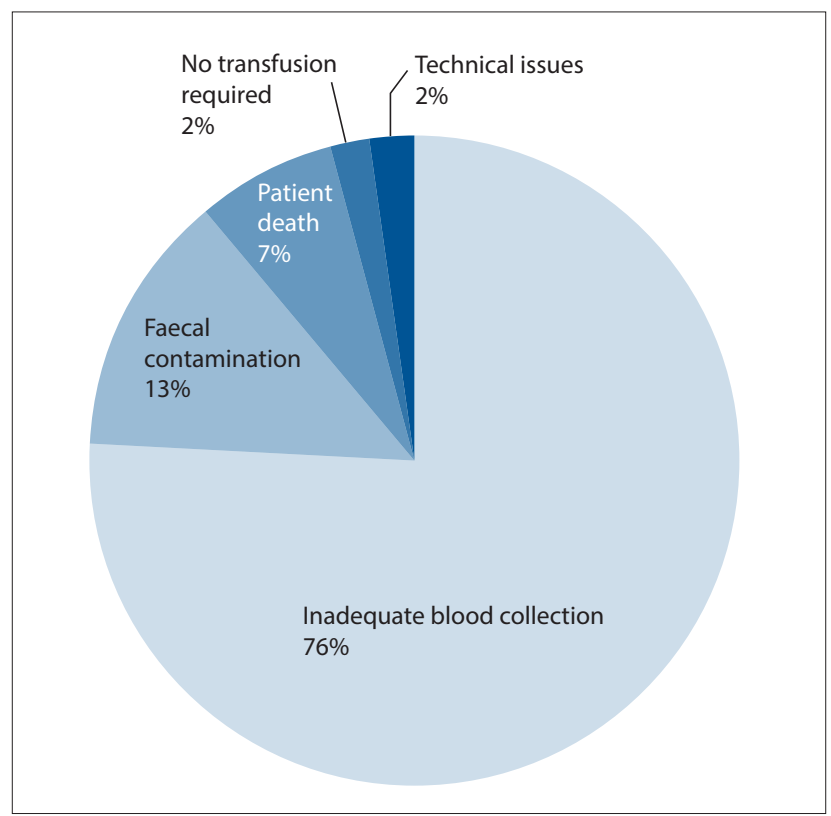

Fig. 4. Reasons for not proceeding to processing of collected blood. for processing in both the PDACCPM protocol and international recommendations. ${ }^{[9]}$

The consumables used for each case were considered and the associated costs were calculated (Table 1).

In the four cases where full setup was performed with production of CS RCC, but where no CS blood was transfused, the reasons were faecal contamination in two cases, technical difficulties in one and perceived inadequate clinical benefit in the fourth.

The costs of Cell Saver consumables and machine costs were compared with the cost of equivalent RCC purchased from SANBS (Fig. 5).

\section{Discussion}

This study showed that intraoperative CS is feasible in the hospital settings of the hospitals surveyed. It was possible to run an effective CS service with existing staff who required short introductory training given by the company providing the equipment. In only 2/144 cases did technical problems preclude CS processing.

There is a justifiable concern that anaesthetic staff might be unable to perform their primary responsibilities if additionally required to operate the Cell Saver. However, only 10 - 15 minutes are required to set up the equipment to initiate collection, with an additional 10 minutes to process each unit of salvaged blood. Since anaesthetic staff are present throughout the procedure and have blood product and transfusion-related experience they are the logical choice for operating the CS systems when technologists are unavailable..$^{[5]}$

This study also showed that CS is potentially beneficial to the community: a significant amount of blood was saved, equating to 186 units of RCC that were not required to be drawn from SANBS and were thus available for other patients.

\section{Table 1. Breakdown of CS consumable use}

\begin{tabular}{lll} 
& \multicolumn{1}{l}{ Cases } & $\begin{array}{l}\text { Total cost } \\
\text { (ZAR) }\end{array}$ \\
\hline Partial setup & 60 & 54300 \\
Full setup (blood reinfused) & 80 & 144547 \\
Full setup (available blood not reinfused) & 4 & 7200 \\
Total consumable use for CS over study & 144 & 206047 \\
period & & \\
ZAR = South African rand; CS = cell salvage. & & \\
\end{tabular}

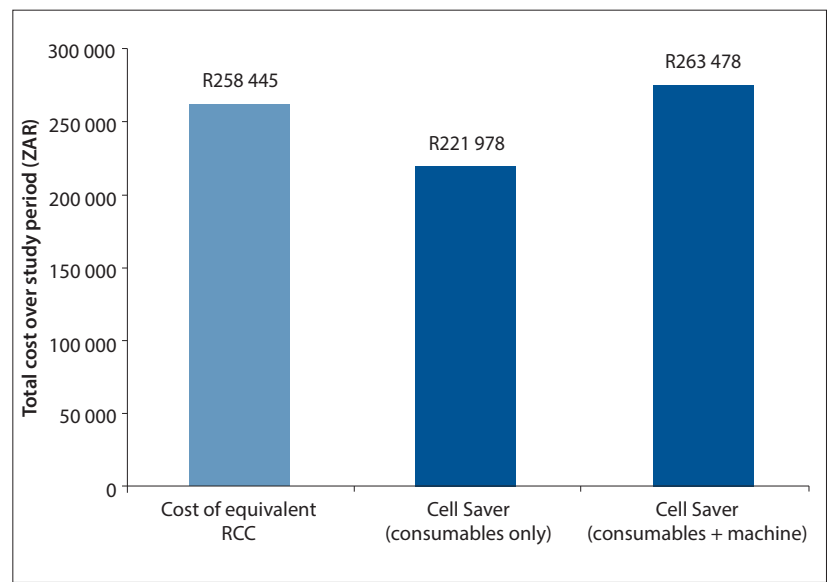

Fig. 5. Blood bank costs compared with Cell Saver costs $(R C C=$ red cell concentrate; $Z A R=$ South African rand). 
There was also obvious benefit to the patients receiving CS blood as in 15 there was no banked blood available due to shortages at the blood bank. Ten of these patients received $\geq 2$ units. CS blood is also available 'immediately', while there is frequently a delay in the delivery of blood from SANBS owing to shortages of supply.

In cases of critical anaemia even single unit transfusions may be of clinical benefit, ${ }^{[13]}$ but the cost of the consumables exceeds that of one unit of RCC. Where $\geq 2$ units have been salvaged, the cost of the CS consumables is less than the equivalent blood bank cost.

We recognise that the current study was not designed to demonstrate clinical benefits or harms of CS use. While the study has identified the high utility of CS in trauma and O\&G patients, it does not allow us to derive predictors of when CS is likely to be of greatest clinical benefit. This area requires further study.

When considering the economic feasibility, the sole published SA study by Bowley et al ${ }^{[2]}$ found intraoperative CS to be cost neutral. This study, however, included only cases with penetrating abdominal wounds and the authors raised the concern that employment of technologists to perform CS would incur prohibitive costs. ${ }^{[3]}$

In our study, the costs of CS blood (consumables only) were lower than purchasing the equivalent RCC from SANBS. When machine depreciation costs are included, the Cell Saver blood became marginally more expensive than RCC. However, Cell Saver costs could be significantly reduced with more stringent guidelines as to when CS should be contemplated. Machine depreciation over five years is also conservative as the machines are reported by the manufacturer to last 8 - 10 years. Even if CS use proves to be marginally more expensive than RCC, it still has the demonstrated ability to provide blood for patients when no other options are available.

In a large proportion of the cases there was inadequate blood collected to justify continuing with Cell Saver processing. This suggests that staff do not always correctly identify appropriate cases and do not predict potential blood loss correctly. However, in almost all cases staff did not proceed to the more expensive step when the inadequate blood loss was recognised, which ameliorated CS disposable costs.

Our study highlighted the fact that the average yield from CS was substantially below those carried in international guidelines which recommend that $800-1000 \mathrm{ml}$ of collected blood should be the equivalent of one unit of washed RCC. In our study, a pooled average of $3136 \mathrm{ml}$ of blood was collected per case, yielding an average of only $697 \mathrm{ml}$ for transfusion after processing. This might be explained by differences in the patient populations in that the majority of cases in our study were emergencies, where a lower initial HCT can be expected, while the international use is generally elective. Further study needs to be done to adequately identify these reasons and refine local protocols as appropriate.

\section{Conclusion}

We have shown that using the Cell Saver is feasible without employing additional staff. The availability of CS blood was beneficial to both the community and the individual patient. Furthermore, using the Cell Saver was economical, with lower or comparable costs to equivalent SANBS RCC. These advantages are particularly relevant in the SA context where blood bank blood is frequently unavailable.

\section{References}

1. Daramola AO, Banjo AA, Elesha SO. Maternal deaths in the Lagos University Teaching Hospital: A ten-year review (1989 - 1998). Niger Postgrad Med J 2004;11(4):274-278.

2. Bowley DB, Barker PB, Boffard KD. Intra-operative blood salvage in penetrating abdominal trauma: A randomised, controlled trial. World J Surg 2006;30(6):1074-1080. [http://dx.doi.org/10.1007/s00268005-0466-2]

3. Osaro E, Charles AT. The challenges of meeting the blood transfusion requirements in Sub-Saharan Africa: The need for the development of alternatives to allogenic blood. J Blood Med 2011;2:7-21. [http://dx.doi.org/10.2147/JBM.S17194]

4. Esper S A, Waters J H. Intra-operative cell salvage: A fresh look at the indications and contraindications. Blood Transfus 2011;9(2):139-147. [http://dx.doi.org/10.2450/2011.0081-10]

5. Szpisjak DF, Potter PS, Capehart BP. Economic analysis of an intra-operative cell salvage service. Anesth Analg 2004;98(1):201-205. [http://dx.doi.org/10.1213/01.ANE.0000093231.53663.DD]

6. Allam J, Cox M, Yentis SM. Cell salvage in obstetrics. Int J Obstet Anaesth 2008;17(1):37-45. [http:// 6. Allam J, Cox M, Yentis SM. Cell salvage
dx.doi.org/10.1016/j.ijoa.2007.08.001]

7. Amand T, Pincemail J, Blaffart F, Larbuisson R, Limet R, Defraigne JO. Levels of inflammatory Amand T, Pincemail J, Blaffart F, Larbuisson R, Limet R, Defraigne JO. Levels of inflammatory
markers in the blood processed by autotransfusion devices during cardiac surgery associated with cardiopulmonary bypass circuit. Perfusion 2002;17(2):117-123. [http://dx.doi.
. org/10.1191/0267659102pf544oa]

8. Waters JH. Cell salvage indications and contraindications. Transfusion 2004;44(S2):40S-44S. [http:// dx.doi.org/10.1111/j.0041-1132.2004.04176.x]

9. The Association of Anaesthetists of Great Britain and Ireland. AAGBI Safety Guideline. Blood Transfusion and the Anaesthetist: Intra-operative Cell Salvage. London: AAGBI, 2009. http://www. aagbi.org/sites/default/files/cell\%20_salvage_2009_amended.pdf (accessed 1 June 2013).

10. SANBS. SANBS State Patients Price List 2012. http://www.sanbs.org.za/PDFDocuments/services/ Productspricelist/state\%20patients\%202012.pdf (accessed 23 August 2013).

1. SANBS. SANBS State Patients Price List 2013. http://www.sanbs.org.za/PDFDocuments/services/ Productspricelist/state\%20patients\%202013.pdf (accessed 23 August 2013).

12. American Hospital Association. Guidelines: Useful Life for Depreciation. http://www.aha.org/ research/rc/stat-studies/data-and-directories.shtml (accessed 1 June 2013).

13. Marshall C. Transfusion trigger: When to transfuse. Crit Care 2004;8(Suppl 2):S31-S33. [http://dx.doi. org/10.1186/cc2846]

Accepted 20 August 2013. 